\title{
Thenar oxygen saturation during weaning from mechanical ventilation: an observational study
}

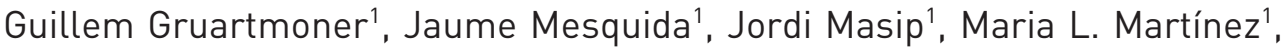 \\ Ana Villagra', Francisco Baigorri', Michael R. Pinsky² and Antonio Artigas ${ }^{1}$
}

\section{Affiliations:}

${ }^{1}$ Critical Care Center, Hospital de Sabadell, Consorci Sanitari Universitari Parc Tauli, Universitat Autònoma de Barcelona, CIBER Enfermedades Respiratorias, Barcelona, Spain.

${ }^{2}$ Dept of Critical Care Medicine, University of Pittsburgh, Pittsburgh, PA, USA.

Correspondence: J. Mesquida, Critical Care Center, Hospital de Sabadell, Tauli, s/n, 08208 Sabadell, Spain. E-mail: jmesquidaatauli.cat

ABSTRACT Our aim was to determine whether thenar tissue oxygen saturation $\left(\mathrm{StO}_{2}\right)$, measured by noninvasive near-infrared spectroscopy, and its changes derived from an ischaemic challenge are associated with weaning outcome.

Our study comprised a prospective observational study in a 26-bed medical-surgical intensive care unit. Patients receiving mechanical ventilation for $>48 \mathrm{~h}$, and considered ready to wean by their physicians underwent a 30-min weaning trial. $\mathrm{StO}_{2}$ was measured continuously on the thenar eminence. A transient vascular occlusion test was performed prior to and at the end of the 30-min weaning trial, in order to obtain $\mathrm{StO}_{2}$ deoxygenation and reoxygenation rates, and estimated local oxygen consumption.

37 patients were studied. Patients were classified as weaning success $(n=24)$ or weaning failure $(n=13)$. No significant demographic, respiratory or haemodynamic differences were observed between the groups at inclusion. Patients who failed the overall weaning process showed a significant increase in deoxygenation and in local oxygen consumption from baseline to $30 \mathrm{~min}$ of weaning trial, whereas no significant changes were observed in the weaning success group.

Failure to wean from mechanical ventilation was associated with higher relative increases in deoxygenation after $30 \mathrm{~min}$ of spontaneous ventilation.

@ERSpublications

Failure to wean from mechanical ventilation is associated with increases in deoxygenation after spontaneous ventilation http://ow.ly/pUn5B

Received: Aug 102012 | Accepted after revision: Dec 12 2012 | First published online: Jan 112013

Support statement: This pilot study received the 2009 European Society of Intensive Care Medicine (ESICM) ECCRN Clinical Investigation Award (ECCRN Clinical Research Award 2009).

Conflict of interest: Disclosures can be found alongside the online version of this article at www.erj.ersjournals.com 


\section{Introduction}

Discontinuation of ventilatory support in critical care medicine can be a difficult challenge in about onethird of patients [1]. Failure to wean from mechanical ventilation (MV) is difficult to predict [2]. Furthermore, failed extubation is associated with increased hospital mortality, prolonged intensive care unit and hospital stays, and increased need for tracheostomy [3].

As spontaneous ventilation is a form of cardiovascular stress test, failure to wean from MV often reflects cardiovascular insufficiency owing to the increased oxygen cost of breathing [4,5]. Normally, any increased oxygen cost of breathing is met by an increased respiratory muscle blood flow, which, in flow-limited states, will divert blood flow away from other tissues, such as the splanchnic and the peripheral circulation [6], and may lead to their hypoperfusion [7-11].

Recently, skeletal muscle oxygen saturation on the thenar eminence $\left(\mathrm{StO}_{2}\right)$ measured noninvasively using near-infrared spectroscopy (NIRS) has been proposed as an early and reliable measure of hypoperfusion states [12-14]. This proposal is based on the idea of the peripheral and splanchnic circulation shunting in low flow states, where blood flow is diverted from less-vital to more-vital areas, such as the heart, brain and respiratory muscles. In addition to reporting steady-state $\mathrm{StO}_{2}$ [15-17], functional monitoring using a transient total vascular occlusion allows for further assessment of cardiovascular state. The dynamic vascular occlusion test (VOT) creates the novel $\mathrm{StO}_{2}$ parameters deoxygenation rate $\left(\mathrm{DeO}_{2}\right)$ and, upon removal, reoxygenation rate $\left(\mathrm{ReO}_{2}\right)$, which improve the predictive value of $\mathrm{StO}_{2}$ in certain critically ill populations $[18,19]$.

We postulated that NIRS monitoring would demonstrate significant hypoperfusion of peripheral skeletal muscle in patients during unsuccessful attempts to wean from MV. The purpose of this study was to analyse whether $\mathrm{StO}_{2}$ and its VOT-derived changes can be useful in predicting weaning outcome in critically ill patients.

\section{Material and methods}

This prospective observational study was conducted in a 26-bed medical-surgical intensive care unit at a university hospital (Hospital de Sabadell, Barcelona, Spain). This study was approved by the Institutional Review Board at the Hospital de Sabadell. Informed consent was obtained from either the patient or their next of kin prior to the study initiation.

We included adult patients (aged $\geqslant 18$ years) receiving invasive $\mathrm{MV}$ for $>48 \mathrm{~h}$ and considered ready to wean by their physicians according to the following criteria: partial or complete recovery from the underlying cause of acute respiratory failure; adequate gas exchange, as indicated by an arterial oxygen tension of $>60$ Torr $(7.99 \mathrm{kPa})$ and an inspiratory oxygen fraction $\left(\mathrm{FIO}_{2}\right)$ of $<0.4$, with a positive endexpiratory pressure of $<5 \mathrm{cmH}_{2} \mathrm{O}$; a core temperature of $<38^{\circ} \mathrm{C}$; haemoglobin $>8 \mathrm{~g} \cdot \mathrm{dL}^{-1}$; and no further need for vasoactive and/or sedative agents.

Exclusion criteria were trauma in both upper limbs, and haematoma or skin lesions at the thenar eminence that could hinder placement of a NIRS sensor probe. Patients with an altered level of consciousness that could lead to central hypoventilation and/or impaired secretion management were also excluded.

\section{Study protocol}

After inclusion, patients underwent a weaning trial (WT) for $30 \mathrm{~min}$, defined as assisted spontaneous breathing with continuous positive airway pressure of $5 \mathrm{cmH}_{2} \mathrm{O}$, or a T-tube trial, according to their medical team. Patients were in a semi-recumbent position, and the $\mathrm{FIO}_{2}$ was kept constant during the trial.

The evaluation criteria for WT failure were defined as the presence of one or more of the following during the 30 -min trial: a respiratory rate of $>35$ breaths $\cdot \mathrm{min}^{-1}$ for $\geqslant 5 \mathrm{~min}$; an arterial oxygen saturation measured by pulse oximetry $<90 \%$, heart rate $>140$ beats $\cdot \mathrm{min}^{-1}$ or sustained increase or decrease in heart rate of $>20 \%$; a systolic blood pressure $>180 \mathrm{mmHg}$ or $<90 \mathrm{mmHg}$; increased anxiety; and diaphoresis. The decision to remove the endotracheal tube was made independently of the study investigators at the end of a successful WT by their attending physicians, who did not have access to the specific $\mathrm{StO}_{2}$ data. Weaning success was defined as a patient remaining free of mechanical ventilatory support for $>24 \mathrm{~h}$ after passing the WT. Weaning failure was defined as either failure to pass the WT (WT failure) or reinstitution of MV within $24 \mathrm{~h}$ of extubation (extubation failure) (fig. 1).

\section{Methods}

Demographic data, age, sex, diagnosis and days on MV, were collected. Haemodynamic, respiratory and oxygenation variables were monitored continuously and recorded just before starting and at $30 \mathrm{~min}$ into the WT. Heart rate and mean systemic arterial pressure (mAP) were recorded by routine bedside monitoring (Monitor Intellivue MP 70; Phillips Medizinsystems, Boeblingen, Germany). Respiratory rate, tidal volume, minute ventilation, $\mathrm{FIO}_{2}$ and arterial oxygen saturation measured by pulse oximetry were recorded at start 
FIGURE 1 Flow chart of patients recruited in the study. Patients who were extubated without reinstitution of mechanical ventilation (MV) within $24 \mathrm{~h}$ were considered to be a "weaning success" $(n=24)$. Patients who failed either the weaning trial (WT) or were extubated but required reinstitution of MV within 24 hours were considered to be a "weaning failure" ( $\mathrm{n}=13)$.

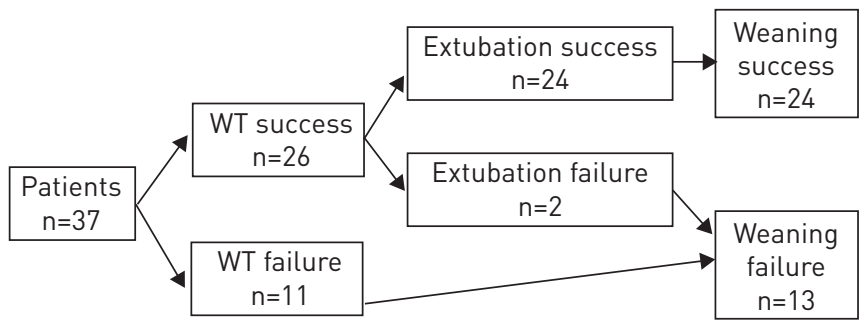

and 30 min into the WT (Monitor Intellivue MP 70; Phillips Medizinsystems). Arterial blood gas analysis was performed before and $30 \mathrm{~min}$ into the WT (ABL 700 series; Radiometer Medical, Copenhagen, Denmark). $\mathrm{StO}_{2}$ was recorded continuously using the InSpectra 650 Tissue Spectrometer (Hutchinson Technology, Hutchinson, MN, USA). The $\mathrm{StO}_{2} 15-\mathrm{mm}$ optical surface probe was placed on intact skin on the thenar eminence; it was never placed adjacent to the site of radial artery cannulation. The InSpectra Tissue Spectrometer also measures relative haemoglobin concentration in the NIRS field of view, which is presented as the tissue haemoglobin index (THI).

\section{Vascular occlusion test}

The VOT was performed as previously described by GÓMEz et al. [18]. Briefly, a blood pressure cuff is placed proximal to the hand on the forearm and rapidly inflated to $40 \mathrm{mmHg}$ above systolic pressure and kept inflated until $\mathrm{StO}_{2}$ decreases to $40 \%$. Then the cuff is rapidly deflated and the rate of increase in $\mathrm{StO}_{2}$ noted. The resulting $\mathrm{DeO}_{2}$ and $\mathrm{ReO}_{2}$ slopes are reported as change in oxygensaturation over time. We performed a VOT at the beginning of the WT and again at $30 \mathrm{~min}$ into the WT, giving $\mathrm{DeO}_{2}$ and $\mathrm{ReO}_{2}$ data paired for each time-point. Using the $\mathrm{DeO}_{2}$ slope and the THI values at the beginning and at the end of the VOT, we also calculated the NIRS-derived thenar muscle oxygen consumption ( $\left.\operatorname{nir} V^{\prime} \mathrm{O}_{2}\right)$, as described by the equation of SKARDA et al. [20]: $\operatorname{nir} V^{\prime} \mathrm{O}_{2}=\left(\mathrm{DeO}_{2} \text { slope }\right)^{-1} /((\mathrm{THI}$ start+THIend $) / 2)$. Relative changes in $\mathrm{StO}_{2^{-}}$ derived parameters were calculated as the quotient between values at $30 \mathrm{~min}$ and baseline. Absolute $\mathrm{StO}_{2}$ and VOT-derived variables were obtained automatically using the InSpectra Research Software ${ }$ v4.01 (Hutchinson Technology).

\section{Analysis}

A descriptive analysis was performed. The Kolmogorov-Smirnov test was used to verify the normality of distribution of the studied variables. Continuous variables are presented as median values with interquartile ranges. The Wilcoxon test was used to analyse changes over time in the paired variables. For continuous variables, the Mann-Whitney U-test and, for categorical variables, Fisher's exact test were used to compare failure and success groups. Data were analysed using the SPSS 17.0 Software (Chicago, IL, USA). Statistical significance was defined as $\mathrm{p}<0.05$ (two-tailed test).

\section{Results}

37 patients were studied. Patient baseline characteristics are summarised in table 1. 26 patients succeeded at the WT and were extubated. However, two of the patients who were extubated required instauration of MV within $24 \mathrm{~h}$ (extubation failure). 11 patients failed the WT (fig. 1). No baseline differences in demographic, haemodynamic and respiratory variables were observed when comparing success and failure groups (table 1), except for lower baseline heart rate in those patients who failed the weaning process (median 78 (interquartile range 71-91) versus 90 (77-95); $\mathrm{p}=0.04)$.

The evolution of the main studied variables is shown in table 2. After 30 min of WT, both patients who succeed and patients who failed the overall weaning process showed a significant increase in respiratory rate and heart rate, with no other changes in their haemodynamic, respiratory and oxymetric parameters.

\section{$\mathrm{StO}_{2}$ variables}

No differences were observed in baseline $\mathrm{StO}_{2}$ parameters between the two groups (table 2). When analysing the evolution of NIRS-derived parameters, patients who succeeded and patients who failed showed different patterns. The weaning success group showed no significant changes in steady-state $\mathrm{StO}_{2}, \mathrm{DeO}_{2}, \mathrm{ReO}_{2}$ and $\operatorname{nir} V^{\prime} \mathrm{O}_{2}$ after $30 \mathrm{~min}$ of WT, whereas the weaning failure group showed a significant decrease in their $\mathrm{DeO}_{2}$ slope (from -11.2 (-16.9--7)\% $\mathrm{min}^{-1}$ to $-13.7(-18.7--7.9) \% \cdot \mathrm{min}^{-1} ; \mathrm{p}=0.04$ ) (fig. 2), as well as an increase in $\operatorname{nir} V^{\prime} \mathrm{O}_{2}$ (from $92(76-146)$ to $\left.141(93-212) \mathrm{U} ; \mathrm{p}=0.04\right)$ after $30 \mathrm{~min}$ of WT. Changes in local haemoglobin content (THI) were not different between the success and failure groups (from 9.9 (8.1-11.9) U 
TABLE 1 Patient baseline characteristics prior to the weaning trial

\begin{tabular}{|c|c|c|c|c|}
\hline & All patients & Weaning success & Weaning failure & p-value ${ }^{\#}$ \\
\hline Subjects $n$ & 37 & 24 & 13 & \\
\hline Age years & $71(56-79)$ & $71(58-79)$ & $73(48-79)$ & 1 \\
\hline Sex male/female & $24 / 13$ & $16 / 8$ & $8 / 5$ & 0.7 \\
\hline \multicolumn{5}{|l|}{ Pre-existent comorbidities } \\
\hline Sleep apnoea & $4(11)$ & $4(17)$ & $0(0)$ & 0.6 \\
\hline COPD & $10(27)$ & $7(29)$ & $3(15)$ & \\
\hline Coronary disease & $10(27)$ & $6(25)$ & $4(31)$ & \\
\hline $\mathrm{CHF}$ & $11(30)$ & $7(29)$ & $4(31)$ & \\
\hline No previous disease & $15(41)$ & $8(33)$ & $3(15)$ & \\
\hline \multicolumn{5}{|l|}{ Aetiology of ARF } \\
\hline Septic shock & $20(54)$ & $12(50)$ & $8(62)$ & 0.6 \\
\hline Acute heart failure & $7(19)$ & $5(20)$ & $2(9)$ & \\
\hline Trauma & $5(14)$ & $4(17)$ & $1(8)$ & \\
\hline Other & $5(14)$ & $3(13)$ & $2(15)$ & \\
\hline Time on MV days & $6(4-10)$ & $5(4-10)$ & $6(4-11)$ & 0.5 \\
\hline Heart rate beats $\cdot \min ^{-1}$ & $88(74-95)$ & 90 (77-95) & $78(71-91)$ & 0.04 \\
\hline Systolic BP mmHg & $126(113-137)$ & $125(117-137)$ & $127(109-145)$ & 0.9 \\
\hline $\mathrm{mAP} \mathrm{mmHg}$ & $80(71-89)$ & $80(76-89)$ & $80(69-88)$ & 0.6 \\
\hline Respiratory rate breaths $\cdot \min ^{-1}$ & $18(17-21)$ & $18(16-21)$ & $19(17-23)$ & 0.1 \\
\hline $\mathrm{PaO}_{2} / \mathrm{FlO}_{2}$ & $262(229-341)$ & $276(240-317)$ & $243(209-380)$ & 0.8 \\
\hline $\mathrm{SpO}_{2} \%$ & 97 (95-98) & 97 (95-98) & 97 (95-98) & 0.2 \\
\hline Tidal volume $\mathrm{mL}$ & $460(390-500)$ & $467(385-500)$ & $440(400-502)$ & 0.7 \\
\hline PEEP $\mathrm{cmH}_{2} \mathrm{O}$ & $5(5-5)$ & $5(5-5)$ & $5(5-6)$ & 0.2 \\
\hline $\mathrm{FlO}_{2} \%$ & $30(28-35)$ & $30(30-35)$ & $30(28-32)$ & 0.2 \\
\hline $\mathrm{pH}$ & $7.48(7.42-7.49)$ & $7.47(7.41-7.5)$ & $7.48(7.44-7.5)$ & 0.7 \\
\hline $\mathrm{PCO}_{2}$ Torr & $35(30-39)$ & 35 (29-39) & $36(32-40)$ & 0.5 \\
\hline Base deficit $\mathrm{mmol} \cdot \mathrm{L}^{-1}$ & $2.6(-2.3-5)$ & $2.1(-2.5-5)$ & $3.9(-1.3-5.4)$ & 0.5 \\
\hline Haemoglobin $\mathrm{mg} \cdot \mathrm{dL}^{-1}$ & $9.1(8.4-10.1)$ & $8.9(8.3-9.9)$ & $9.2(8.7-11.4)$ & 0.3 \\
\hline $\mathrm{ScvO}_{2} \%$ & $65(55-71)$ & $66(51-71)$ & $61(57-76)$ & 1 \\
\hline \multicolumn{5}{|c|}{$\begin{array}{l}\text { Data are presented as median (interquartile range), } \mathrm{n} / \mathrm{n} \text { or } \mathrm{n}(\%) \text {, unless otherwise stated. COPD: chronic obstructive pulmonary disease; } \mathrm{CH} \\
\text { congestive heart failure; } \mathrm{ARF} \text { : acute respiratory failure; } \mathrm{MV}: \text { mechanical ventilation; } \mathrm{BP} \text { : blood pressure; mAP: mean arterial pressure; Pad } \\
\text { arterial oxygen tension; } \mathrm{FlO}_{2} \text { : inspiratory oxygen fraction; } \mathrm{SpO}_{2} \text { : arterial oxygen saturation measured by pulse oximetry; PEEP: positive en } \\
\text { expiratory pressure; } \mathrm{PCO}_{2}: \text { carbon dioxide tension; } \mathrm{ScvO}_{2}: \text { central venous oxygen saturation. \# : between weaning success and failure. }\end{array}$} \\
\hline
\end{tabular}

to 10.5 (8.5-12.9) U, $\mathrm{p}<0.01$, in the success group; and from $10.1(7.8-11.1) \mathrm{U}$ to $10.4(7.7-13) \mathrm{U}, \mathrm{p}=0.03$, in the failure group).

The $\mathrm{DeO}_{2}$ ratio (represented as the ratio of $\mathrm{DeO}_{2}$ at 30 min to baseline $\mathrm{DeO}_{2}$ ) was significantly higher in the failure group $(1.03(0.92-1.22)$ in the success group versus $1.27(1.12-1.49)$ in the failure group; $\mathrm{p}<0.01)$ (fig. 3). In addition, the nir $\mathrm{OO}_{2}$ ratio (the increase in nir $\mathrm{O}_{2}$ during the $\mathrm{WT}$, represented as the ratio of nir $\mathrm{VO}_{2}$ at $30 \mathrm{~min}$ to baseline nir $\left.\mathrm{OO}_{2}\right)$ was also higher in the failure group $(1.1(0.8-1.3)$ in the success group versus $1.24(1.21-1.66)$ in the failure group; $\mathrm{p}=0.02)$.

\section{Discussion}

The main observation of the present study is that higher relative increases in $\mathrm{StO}_{2}, \mathrm{DeO}_{2}$ rate and local skeletal muscle oxygen consumption (nir $V^{\prime} \mathrm{O}_{2}$ ) after a $30 \mathrm{~min}$ WT are associated with failure to wean from MV.

Changing from positive-pressure ventilation to spontaneous breathing determines an increase in the work of breathing and, thus, an increase in the oxygen demand of the respiratory muscles. If the metabolic demand of transitioning from MV to spontaneous ventilation cannot be met by increasing cardiac output, either because cardiovascular reserve is limited, the work cost of breathing excessive, or both, then the cardiovascular system addresses these excessive demands by increasing sympathetic tone, which tries to maximise cardiac output [21], while redistributing blood flow away from the periphery and splanchnic circulation to the respiratory muscles [22, 23]. Such increased sympathetic activity also increases tissue metabolic rate. Accordingly, blood flow redistribution and increased tissue oxygen consumption could coexist in patients during a failed WT. 
TABLE 2 Characteristics at baseline and at 30 min of weaning trial

\begin{tabular}{|c|c|c|c|c|}
\hline & \multicolumn{2}{|c|}{ Weaning success } & \multicolumn{2}{|c|}{ Weaning failure } \\
\hline & Baseline & $30 \mathrm{~min}$ & Baseline & $30 \min ^{\#}$ \\
\hline Subjects & \multicolumn{2}{|c|}{24} & \multicolumn{2}{|c|}{13} \\
\hline Heart rate beats $\cdot \min ^{-1}$ & 90 (77-95) & $95(81-100)^{*}$ & $78(71-91)^{\bullet}$ & $91(85-98)^{*}$ \\
\hline Systolic BP mmHg & 125 (117-137) & $127(119-141)$ & 127 (109-145) & $120(113-157)$ \\
\hline mAP $\mathrm{mmHg}$ & $80(76-89)$ & $81(76-89)$ & $80(69-88)$ & $83(72-94)$ \\
\hline Respiratory rate breaths $\cdot \min ^{-1}$ & $18(16-21)$ & $24(17-27)^{*}$ & $19(17-23)$ & $35(28-36)^{*}$ \\
\hline $\mathrm{SpO}_{2} \%$ & 97 (95-98) & $96(94-98)$ & 97 (95-98) & $95(90-96)$ \\
\hline Tidal volume $\mathrm{mL}$ & $467(385-500)$ & $450(370-540)$ & $440(400-502)$ & $285(237-326)^{*, 9}$ \\
\hline $\mathrm{pH}$ & $7.47(7.41-7.5)$ & $7.45(7.39-7.48)$ & $7.48(7.44-7.5)$ & $7.45(7.4-7.47)$ \\
\hline $\mathrm{PCO}_{2}$ Torr & $35(29-39)$ & $37(30-41)$ & $36(32-40)$ & $39(34-43)$ \\
\hline Base deficit mmol $\cdot \mathrm{L}^{-1}$ & $2.1(-2.5-5)$ & $1.1(-1.5-3.6)$ & $3.9(-1.3-5.4)$ & $3(-2.1-4.8)$ \\
\hline $\mathrm{StO}_{2} \%$ & $79(75-84)$ & $81(76-84)$ & $77(73-83)$ & $75(72-88)$ \\
\hline THI U & $9.9(8.1-11.9)$ & $10.5(8.5-12.9)^{*}$ & $10.1(7.8-11.1)$ & $10.4(7.7-13)^{*}$ \\
\hline $\mathrm{DeO}_{2} \% \cdot \mathrm{min}^{-1}$ & $-12.4(-16.4--9.8)$ & $-12.7(-16.5--10.5)$ & $-11.2(-16.9--7)$ & $-13.7(-18.7--7.9)^{*} \cdot$ \\
\hline $\mathrm{ReO}_{2} \% \cdot \min ^{-1}$ & 185 (144-252) & 205 (137-293) & 217 (181-309) & $261(222-365)$ \\
\hline nir $V^{\prime} \mathrm{O}_{2} \mathrm{U}$ & $109(90-158)$ & $114(66-168)$ & $92(76-146)$ & $141(93-212)^{*}$ \\
\hline $\begin{array}{l}\text { Respiratory rate/VT } \\
\text { breaths } \cdot \min ^{-1} \cdot \mathrm{L}^{-1}\end{array}$ & & $49(33-68)$ & & $133(85-169)^{\top}$ \\
\hline $\mathrm{StO}_{2}$ ratio & & $1.0(0.96-1.05)$ & & $0.99(0.97-1.03)$ \\
\hline $\mathrm{DeO}_{2}$ ratio & & $1.03(0.92-1.22)$ & & $1.27(1.12-1.49)^{\circ}$ \\
\hline $\mathrm{ReO}_{2}$ ratio & & $1.06(0.88-1.25)$ & & $1.08(0.92-1.7)$ \\
\hline THI ratio & & $1.05(1.02-1.19)$ & & $1.04(0.98-1.07)$ \\
\hline nir $V^{\prime} \mathrm{O}_{2}$ ratio & & $1.1(0.8-1.3)$ & & $1.24(1.21-1.66)^{\pi}$ \\
\hline \multicolumn{5}{|c|}{ 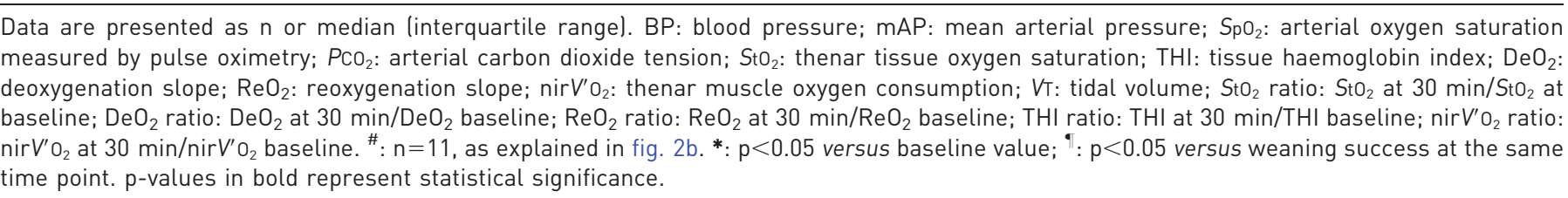 } \\
\hline
\end{tabular}

Assessing blood flow redistribution in the splanchnic bed via monitoring splanchnic tissue hypoxia has proven to be a useful tool to predict weaning outcome $[9,11]$. Despite some initial promising results [8-11], gastric tonometry was not evaluated in large studies. Furthermore, this technique did not become a routine standard of care due to its technological requirements and difficult application at the bedside. As occurs with the splanchnic area, noninvasive monitoring of the peripheral circulation might add potential benefits to cardiovascular performance assessment. In our study, we hypothesised that presumed cardiovascular overload of excessive cost of breathing would be detected by noninvasive regional evaluation of skeletal muscle oxygenation using NIRS technology.

As we already expected, we did not observe significant changes in $\mathrm{StO}_{2}$ during the spontaneous breathing trial in any of the two groups. Although steady-state $\mathrm{StO}_{2}$ has been proposed as a marker of hypoperfusion states, especially in haemorrhagic shock [24], our group and others have already demonstrated the lack of sensitivity of the absolute $\mathrm{StO}_{2}$ value $[15,16,25]$, suggesting that absolute steady-state $\mathrm{StO}_{2}$ might not detect less severe degrees of tissue hypoperfusion. We presumed that during the WT there would not be enough blood flow redistribution to be detected by static NIRS measurements.

However, dynamic NIRS-derived variables created by an ischaemic challenge, $\mathrm{DeO}_{2}$ and $\mathrm{ReO}_{2}$, provide more information about tissue wellness, exploring the local metabolic rate and the endothelial integrity, respectively. These novel parameters have been studied mostly in trauma and septic-shock patients, were they have consistently shown prognostic implications, independently from other cardiovascular parameters $[26,27]$.

In our set of patients, the relative increase in $\mathrm{DeO}_{2}$ during a 30 min WT was associated with weaning failure. $\mathrm{DeO}_{2}$ is a dynamic parameter that depends on the local $\mathrm{O}_{2}$ supply-demand relationship and mirrors local oxygen utilisation. Increases in $\mathrm{DeO}_{2}$ might be explained by two different, and cumulative, mechanisms: 1) by a local supply-demand dependency in low or inadequate flow states, such as blood flow redistribution; and 2) by an increased metabolic rate. During spontaneous breathing, if there is an increase in respiratory muscle demand, leading to sympathetically mediated peripheral vasoconstriction and blood 

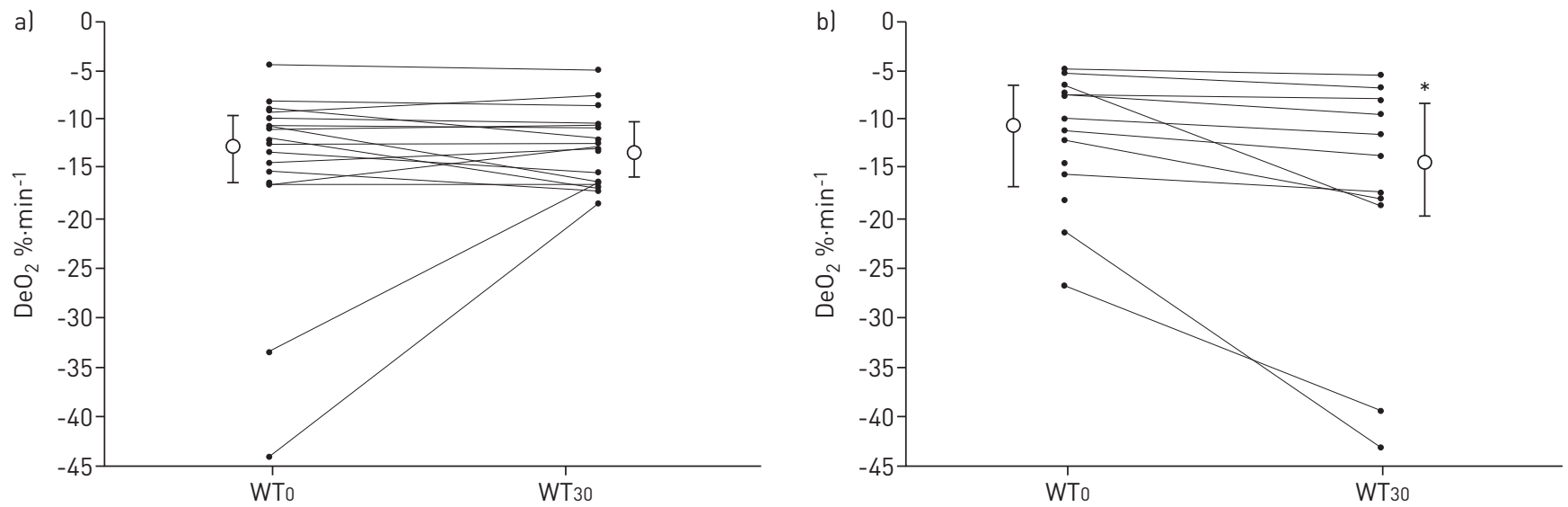

FIGURE 2 Deoxygenation $\left(\mathrm{DeO}_{2}\right)$ slope at baseline weaning trial (WT0) and 30 min after beginning the WT (WT30) for patients who a) succeeded or b) failed the overall WT. $\mathrm{DeO}_{2}$ values for each patient (closed circles), and the median (interquartile range) value of $\mathrm{DeO}_{2}$ at baseline and after 30 mins of WT (open circles) are shown. Two patients in the weaning failure group (shown in b) did not complete the WT, requiring reinstitution of mechanical ventilation, because of increased respiratory efforts, sweating and arterial oxygen desaturation. ${ }^{*}: \mathrm{p}<0.05$, when comparing paired $\mathrm{DeO}_{2}$ at 30 min and baseline $\mathrm{DeO}_{2}$.

flow redistribution, inadequate local flow could lead to increased local oxygen extraction. In such cases, in addition to higher $\mathrm{DeO}_{2}$ rates, one would expect to see reduced THI values in the failure group, as compared with the successfully weaned patients, reflecting lower tissue haemoglobin content in blood flow redistribution conditions. Indeed, BARTELS et al. [17] demonstrated that thenar eminence THI decreased significantly during blood flow redistribution induced by simulated hypovolaemia (i.e. lower body negative pressure). In our study, however, we did not observe any differences in THI behaviour during the WT between the two groups. Although, as occurs with absolute $\mathrm{StO}_{2}$, THI might be not sensitive enough to detect mild decreases in local blood flow, during the spontaneous breathing trial, both groups showed a THI increase suggesting, if any, an increase in cardiac output in response to the reinitiation of spontaneous ventilation. Therefore, the observed increase in $\mathrm{DeO}_{2}$ in the failure group might be mostly related to local oxygen consumption. This hypothesis was also supported by nir $V^{\prime} \mathrm{O}_{2}$ evolution, an estimation of local oxygen consumption that corrects $\mathrm{DeO}_{2}$ for the local haemoglobin content [20]. This finding might reflect increased sympathetic outflow trying to compensate for the inadequate cardiovascular response, as supported by other studies that showed a significant increase in plasma catecholamine levels during WT, especially in failure to wean patients [28-30].

In summary, in the present observational study, higher $\mathrm{DeO}_{2}$ and $\operatorname{nir} V^{\prime} \mathrm{O}_{2}$ during WT were associated with weaning failure. Our findings suggest that these functional parameters might detect increased local oxygen consumption secondary to increased sympathetic tone in failure to wean patients.

\section{Study limitations}

Some limitations of the present study should be acknowledged. First, the study was carried out in a single centre. Although we expect that similar patients should behave similarly, weaning approaches may vary

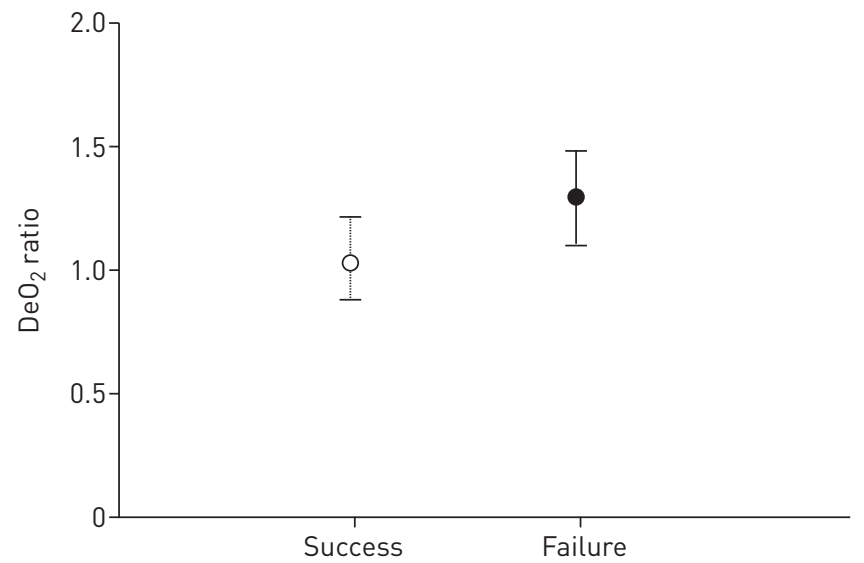

FIGURE 3 Deoxygenation ratio $\left(\mathrm{DeO}_{2}\right)$ for weaning success and failure. $\mathrm{DeO}_{2}$ for the weaning success and failure groups, represented as median (interquartile range), were statistically different with $\mathrm{p}<0.01$. 
across centres, thereby degrading the predictive value of these $\mathrm{StO}_{2}$-derived parameters. Thus, this study needs to be duplicated across other centres. Secondly, our pilot study had a small sample size, and only 13 patients presented weaning failure (with only two extubation failures). It would be especially interesting to evaluate the predictive utility of these parameters in preventing extubation failure, which could not be addressed in our pilot study. Clearly, a larger study would allow refined investigation into the interactions of processes and calibration of the predictive parameters that were primarily identified in this study. Thirdly, we did not determine the cause of weaning failure in patients who were considered to fail. We merely identified that they did fail. We can expect different behaviours of $\mathrm{StO}_{2}$ parameters in patients who fail because of limited cardiovascular reserve from patients who fail because of upper airway obstruction and/or impaired secretions management. This issue must be taken into account in future studies exploring weaning failure.

\section{Conclusions}

Relative changes in $\mathrm{StO}_{2}$ VOT-derived $\mathrm{DeO}_{2}$ slopes and local oxygen consumption after 30 min of a WT were associated with weaning outcome. Thus, $\mathrm{StO}_{2}$ changes derived from a VOT might be a useful clinical tool to predict weaning outcome.

\section{Acknowledgements}

The authors wish to thank to all the critical care unit staff in Hospital de Sabadell, Barcelona, Spain.

\section{References}

1 Esteban A, Frutos F, Tobin MJ, et al. A comparison of four methods of weaning patients from mechanical ventilation. N Engl J Med 1995; 332: 345-350.

2 Meade M, Guyatt G, Cook D, et al. Predicting success in weaning from mechanical ventilation. Chest 2001; 120: 400S-424S.

3 Esteban A, Alía I, Gordo F, et al. Extubation outcome after spontaneous breathing trials with t-tube or pressure support ventilation. Am J Respir Crit Care Med 1997; 156: 459-465.

4 Field S, Kelly SM, Macklem PT. The oxygen cost of breathing in patients with cardiorespiratory disease. Am Rev Respir Dis 1982; 126: 9-13.

Roussos C, Macklem PT. The respiratory muscles. N Engl J Med 1982; 307: 786-797.

6 Peters J, Mack GW, Lister G. The importance of the peripheral circulation in critical illness. Intensive Care Med 2001; 27: 1446-1458.

7 Magder S, Erian R, Roussos C. Respiratory muscle blood flow in oleic acid-induced pulmonary edema. J Appl Physiol 1986; 60: 1849-1856.

8 Mohsenifar Z, Hay A, Hay J, et al. Gastric intramural $\mathrm{pH}$ as a predictor of success or failure in weaning patients from mechanical ventilation. Ann Intern Med 1993; 119: 794-798.

9 Bouachour G, Guiraud MP, Gouello JP, et al. Gastric intramucosal pH: an indicator of weaning outcome from mechanical ventilation in COPD patients. Eur Respir J 1996; 9: 1868-1873.

10 Hurtado FJ, Berón M, Olivera W, et al. Gastric intramucosal pH and intraluminal PCO2 during weaning from mechanical ventilation. Crit Care Med 2001; 29: 70-76.

11 Bocquillon N, Mathieu D, Neviere R, et al. Gastric mucosal pH and blood flow during weaning from mechanical ventilation in patients with chronic obstructive pulmonary disease. Am J Respir Crit Care Med 1999; 160: $1555-1561$.

12 Taylor DE, Simonson SG. Use of near-infrared spectroscopy to monitor tissue oxygenation. New Horiz 1996; 4: 420-425.

13 Crookes BA, Cohn SM, Bloch S, et al. Can near-infrared spectroscopy identify the severity of shock in trauma patients? J Trauma 2005; 58: 806-813.

14 Beilman GJ, Groehler KE, Lazaron V, et al. NIRS measurement of regional tissue oxyhemoglobin saturation during hemorrhagic shock. Shock 1999; 12: 196-200.

15 Mesquida J, Masip J, Gili G, et al. Thenar oxygen saturation measured by near infrared spectroscopy as a noninvasive predictor of low central venous oxygen saturation in septic patients. Intensive Care Med 2009; 35: 1106-1109.

16 Mesquida J, Gruartmoner G, Martínez ML, et al. Thenar oxygen saturation and invasive oxygen delivery measurements in critically ill patients in early septic shock. Shock 2011; 35: 456-459.

17 Bartels SA, Bezemer R, de Vries FJ, et al. Multi-site and multi-depth near-infrared spectroscopy in a model of simulated (central) hypovolemia: lower body negative pressure. Intensive Care Med 2011; 37: 671-677.

18 Gómez $\mathrm{H}$, Torres A, Polanco P, et al. Use of noninvasive NIRS during a vascular occlusion test to assess dynamic tissue $\mathrm{O}_{2}$ saturation response. Intensive Care Med 2008; 34: 1600-1607.

19 Creteur J, Carollo T, Soldati G, et al. The prognostic value of muscle $\mathrm{StO}_{2}$ in septic patients. Intensive Care Med 2007; 33: 1549-1556.

20 Skarda DE, Mulier KE, Myers DE, et al. Dynamic near-infrared spectroscopy measurements in patients with severe sepsis. Shock 2007; 27: 348-353.

21 Jubran A, Mathru M, Dries D, et al. Continuous recordings of mixed venous oxygen saturation during weaning from mechanical ventilation and the ramifications thereof. Am J Respir Crit Care Med 1998; 158: 1763-1769.

22 Kuwahira I, Gonzalez NC, Heisler N, et al. Changes in regional blood distribution and oxygen supply during hypoxia in conscious rats. J Appl Physiol 1993; 74: 211-214.

23 Hussain S, Roussos C. Distribution of respiratory muscle and organ blood flow during endotoxin shock in dogs. J Appl Physiol 1985; 59: 1802-1808.

24 Taylor JH, Mulier KE, Myers DE, et al. Use of near infrared spectroscopy in early determination of irreversible hemorrhagic shock. J Trauma 2005; 58: 1119-1125. 
Soller BR, Ryan KL, Rickards CA, et al. Oxygen saturation determined from deep muscle, not thenar tissue, is an early indicator of central hypovolemia in humans. Crit Care Med 2008; 36: 176-182.

26 Guyette FX, Gomez H, Suffoletto B, et al. Prehospital dynamic tissue oxygen saturation response predicts inhospital lifesaving interventions in trauma patients. J Trauma Acute Care Surg 2012; 72: 930-935.

27 Mesquida J, Espinal C, Gruartmoner G, et al. Prognostic implications of tissue oxygen saturation in human septic shock. Intensive Care Med 2012; 38: 592-597.

28 Frazier SK, Stone KS, Moser D, et al. Hemodynamic changes during discontinuation of mechanical ventilation in medical intensive care unit patients. Am J Crit Care 2006; 15: 580-593.

29 Lemaire F, Teboul JL, Cinotti L, et al. Acute left ventricular dysfunction during unsuccessful weaning from mechanical ventilation. Anesthesiology 1988; 69: 171-179.

30 Oh TE, Bhatt S, Lin ES, et al. Plasma catecholamines and oxygen consumption during weaning from mechanical ventilation. Intensive Care Med 1991; 17: 199-203. 